\title{
Estudo Comparativo da Biologia de Meloidogyne enterolobii (= M. mayaguensis) e Meloidogyne javanica em Tomateiros com Gene $M i$
}

\author{
Juliana Nogueira Westerich*, Juliana Magrinelli Osório Rosa, Silvia Renata Siciliano Wilcken
}

Setor de Defesa Fitossanitária, Departamento de Produção Vegetal, Faculdade de Ciências Agronômicas - Universidade Estadual Paulista (FCA - UNESP), 18.610-307 Botucatu (SP) Brasil.

Autor para correspondência: Juliana N. Westerich (julianawesterich@yahoo.com.br)

Data de chegada: 12/03/2010. Aceito para publicação em: 19/01/2011.

1689

\section{RESUMO}

Westerich, J.N.; Rosa, J.M.O.; Wilcken, S.R.S. Estudo comparativo da biologia de Meloidogyne enterolobii (= M. mayaguensis) e Meloidogyne javanica em tomateiros com gene Mi. Summa Phytopathologica, v.37, n.1, p.35-41, 2011.

Visando conhecer a relação parasito hospedeiro de $M$. enterolobii em plantas com resistência a nematoides das galhas, estudos comparativos da biologia de $M$. enterolobii e $M$. javanica em tomateiros com o gene $\mathrm{Mi}$ foram conduzidos. O experimento foi conduzido em esquema fatorial $2 \times 2$, composto de dois porta-enxertos de tomateiro ('Magnet' e 'Helper M') e duas espécies de nematoides das galhas ( $M$. enterolobii e $M$. javanica) com cinco repetições. As plantas foram inoculadas com 500 juvenis infectantes $\left(\mathrm{J}_{2}\right)$ de $M$. enterolobii ou M. javanica. As raízes foram coletadas aos 3, 10, 17,
24 e 31 dias após a inoculação, coloridas com fucsina ácida, e dissecadas sob microscópio estereoscópico para a localização e contagem dos diferentes estádios de desenvolvimento dos nematoides. Os dados foram submetidos à análise de variância e as médias comparadas pelo teste de Tukey a 5\% de probabilidade. Os resultados obtidos mostraram que, embora ambas as espécies tenham sido capazes de penetrar as raízes dos porta-enxertos de tomateiro, somente $M$. enterolobii conseguiu desenvolver-se normalmente, com as fêmeas maduras realizando suas posturas, a partir de 24 dias após a inoculação.

Palavras-chave adicionais: Nematoides das galhas, resistência, nematologia.

\section{ABSTRACT}

Westerich, J.N.; Rosa, J.M.O.; Wilcken, S.R.S. Comparative study of biology of Meloidogyne enterolobii (= M. mayaguensis) and Meloidogyne javanica in tomatoes with Mi gene. Summa Phytopathologica, v.37, n.1, p.35-41, 2011.

In order to know the host parasite relationship of $M$. enterolobii in plants with resistance to nematodes, comparative studies of the biology of $M$. enterolobii and $M$. javanica in tomato with the $M i$ gene were conducted. The experiment was set up in a two-by-two factorial design consisting of two varieties of tomato ('Magnet' and 'Helper M') and two species of root-knot nematodes (M. javanica and $M$. enterolobii) with five replicates. Plants were inoculated with 500 infective juveniles $\left(\mathrm{J}_{2}\right)$ of $M$. enterolobii or $M$. javanica. The root were collected at $3,10,17,24$ and 31 days after inoculation, stained with acid fuchsin, and dissected on stereomicroscope in order to observe the different developmental stages of nematodes. The data were subjected to analysis of variance and means compared by Tukey test at $5 \%$ probability. The results showed that, although both species have been able to penetrate the roots of the rootstocks of tomato, only $M$. enterolobii was able to develop normally, with mature females carrying their egg masses, from 24 days after inoculation.

Palavras-chave adicionais: Root-knot nematodes, resistance, nematology.

O tomateiro (Solanum lycopersicum L.) é uma das principais olerícolas cultivadas no Brasil. $\mathrm{O}$ aumento da área e o cultivo sucessivo dessa solanácea favoreceram o desenvolvimento de pragas e doenças, afetando a produção. Taylor (22) cita que durante anos, estudos vêm sendo realizados no intuito de incorporar resistência à cultura do tomateiro a pragas e doenças de grande importância.

De acordo com Moura (17), as cultivares de tomateiro com resistência à meloidoginose disponíveis no comércio são efetivas contra as espécies M. incognita (Kofoid \& White) Chitwood, M. javanica (Treub) Chitwood e M. arenaria (Neal) Chitwood, mas suscetíveis a M. hapla Chitwood. Segundo Hussey \& Janssen (15) essa resistência é conferida por um gene, $M i$, localizado no cromossomo 6 e oriundo de espécies de tomateiro selvagem L. peruvianum L. Provavelmente, o mais usado e investigado gene de resistência aos nematoides das galhas é o gene $M i$. Este gene foi descrito por Smith em 1944 e tem sido usado há mais de 60 anos.

Atualmente, uma espécie de grande importância é $M$. enterolobii (=M. mayaguensis) que foi descrita por Yang \& Eisenback (26) oriunda de uma população encontrada em raízes de Enterolobium contortisiliquum (Vell.) Morong, na ilha de Hainan, na China. Segundo os mesmos autores, plantas de algodão, fumo 'NC 95', pimentão, melão e tomate são boas hospedeiras de $M$. enterolobii.

No Brasil, a espécie $M$. enterolobii foi assinalada pela primeira vez em Petrolina (PE), Curaçá e Maniçoba (BA), por Carneiro et al. (5), causando danos severos em plantios comerciais de goiabeira. Nesse relato, essa espécie foi denominada de M. mayaguensis, entretanto atualmente tal espécie é considerada sinonímia de $M$. enterolobii, comprovada por estudos de dados morfológicos, gama de hospedeiros, fenótipos para as enzimas EST e MDH e sequências do mtDNA realizados por $\mathrm{Xu}$ et al. (25). 
Segundo Carneiro et al. (5), tal espécie é polífaga, de alta virulência, com potencial de multiplicação superior a $M$. incognita em cultivares suscetíveis de tomateiro, e capaz de vencer a resistência do cultivar Rossol de tomateiro, portadora do gene $M i$, que confere resistência às principais espécies de nematoides das galhas.

Guimarães et al. (12) demonstraram pelo teste de parasitismo de M. enterolobii em tomateiros (Solanum lycopersicum) 'Santa Cruz' e 'Viradouro, portadores do gene $M i$, se mostraram suscetíveis a essa espécie de nematoide das galhas.

Em São Paulo, foi detectada pela primeira vez parasitando o híbrido de pimentão (Capsicum annum L.) 'Silver' e tomateiros 'Andréa' e 'Débora', quebrando a resistência conferida a meloidoginose. Essa espécie de nematoide vem causando perdas nessas culturas em alguns municípios do Estado segundo Carneiro et al. (4).

Cantu et al. (2) determinaram o fator de reprodução de $M$. enterolobii em diferentes porta-enxertos de tomateiros portadores do gene $M i$ disponíveis no mercado brasileiro, os quais variaram de 11,34 (TMA-804) a 18,21 (Dr. K). O tomateiro 'Rutgers' utilizado como padrão de viabilidade do inóculo teve fator de reprodução igual a 17,72 .

Com o objetivo de conhecer a biologia de $M$. enterolobii em tomateiros com o gene $M i$, foram realizados estudos comparando a biologia deste nematoide com a de $M$. javanica.

\section{MATERIAL E MÉTODOS}

O estudo da biologia dos nematoides $M$. enterolobii (= M. mayaguensis) e $M$. javanica foi desenvolvido no Setor de Defesa Fitossanitária do Departamento de Produção Vegetal da Faculdade de Ciências Agronômicas de Botucatu - UNESP.

Os porta-enxertos de tomateiro 'Magnet' e 'Helper $M$ ' foram obtidos a partir de sementes cedidas, respectivamente, pelas Empresas Sakata e Takii. Estas foram semeadas em bandejas de isopor com substrato esterilizado e aos 14 dias após a germinação foram transplantadas para o recipiente definitivo, em copos plásticos de $500 \mathrm{~mL}$ contendo substrato de solo, areia e matéria orgânica (1:2:1), previamente autoclavados.

A população de $M$. enterolobii utilizada para a realização do trabalho foi obtida a partir de cultivo de pimentão 'Silver' de Campos Novos Paulista, SP, e a população de $M$. javanica foi obtida de raízes de pimentão 'Magali', proveniente do município de Santa Rosa, RS. Ambas foram identificadas pelo padrão perineal das fêmeas e pelo padrão eletroforético de isoenzimas conforme técnica proposta por Carneiro \& Almeida (3), no Laboratório da EMBRAPA - Recursos Genéticos e Biotecnologia, em Brasília. As populações foram multiplicadas em raízes de tomateiro 'Rutgers' e mantidas em casa de vegetação (reguladas para não exceder $30^{\circ} \mathrm{C}$ ).

As suspensões de juvenis infectantes utilizadas como inóculo foram obtidas de raízes de tomateiro 'Rutgers' altamente infectadas, processadas de acordo com a técnica proposta por Hussey \& Baker (14) e modificada por Bonetti \& Ferraz (1). A suspensão resultante foi vertida em aparato de Baermann modificado para recipiente raso conforme Southey (21) e colocada em estufa incubadora do tipo B.O.D., a temperatura de $30^{\circ} \mathrm{C}$, por três dias, para eclosão dos juvenis de segundo estádio $\left(\mathrm{J}_{2}\right)$.

Após a primeira hora da instalação das câmaras de extração, a suspensão obtida foi recolhida e descartada para evitar a inclusão dos $\mathrm{J}_{2}$ eclodidos durante o processo de extração. Os $\mathrm{J}_{2}$ utilizados no experimento foram então recolhidos às 24,48 e 72 horas após a montagem das câmaras de extração e ao fim desse período, foi determinado o número médio de $\mathrm{J}_{2}$ na suspensão, com auxílio de lâmina de Peters sob microscópio óptico.

A infestação do solo foi feita com aproximadamente $500 \mathrm{~J}_{2} /$ volume padronizado de suspensão, ou seja, com $4 \mathrm{~mL}$, em quatro orifícios equidistantes com $3 \mathrm{~cm}$ de profundidade ao redor das plantas. Esta foi efetuada uma semana após o transplante dos porta-enxertos estudados. Posteriormente, essas plantas foram mantidas em B.O.D., a $26^{\circ} \mathrm{C}$. O delineamento experimental utilizado foi em esquema fatorial $2 \times 2$, constituído de dois porta-enxertos de tomateiro, 'Magnet e Helper M'; e duas espécies de nematoides das galhas, M. enterolobii e $M$. javanica, com cinco repetições.

Foram realizadas cinco coletas, aos 3, 10, 17, 24 e 31 dias após a inoculação (DAI). Para cada época de coleta, foram retiradas ao acaso, cinco plantas, as quais tiveram as partes aéreas descartadas e os sistemas radiculares, foram cuidadosamente lavados, secados em papel absorvente e pesados. A parcela avaliada constituiu da metade do sistema radicular de cada planta.

As raízes inoculadas foram submetidas à coloração com fucsina ácida e dissecadas sob microscópio estereoscópico para a localização dos diferentes estádios de desenvolvimento de $M$. enterolobii ou $M$. javanica presentes nas raízes.

Preparações microscópicas em meio de glicerina em lâminas de vidro foram feitas quando necessárias, para posterior observação ao microscópio de luz e classificação dos estádios de desenvolvimento dos nematoides, segundo Triantaphyllou \& Hirschmann (24) e Siddiqi \& Taylor (20), bem como a contagem dos referidos estádios de desenvolvimento (Figura 1): juvenil de segundo estádio infestante, sem alteração de forma $\left(\mathrm{J}_{2} \mathrm{a}\right)$; juvenil de segundo estádio em forma de salsicha $\left(\mathrm{J}_{2} \mathrm{~b}\right)$; juvenil de terceiro estádio, após a segunda ecdise, com resquícios de cauda, sem estilete e dentro de duas cutículas $\left(\mathrm{J}_{3}\right)$; juvenil de quarto estádio, após a terceira ecdise, sem estilete, sem cauda e dentro de 3 cutículas $\left(\mathrm{J}_{4}\right)$; fêmea jovem, após a quarta ecdise, sem ovos $\left(\mathrm{F}_{1}\right)$; fêmea com massa de ovos $\left(\mathrm{F}_{2}\right)$ e machos.

O número de juvenis dos diferentes estádios de desenvolvimento das espécies de nematoides foi contado nas cinco épocas de coleta (3, $10,17,24$ e 31 DAI), e a duração do período do seu desenvolvimento determinada, ambos para cada porta-enxerto de tomateiro. Os dados foram submetidos à análise de variância e as médias, após serem

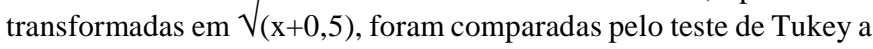
$5 \%$ de probabilidade, utilizando-se o programa Sisvar proposto por Ferreira (10).

\section{RESULTADOS E DISCUSSÃO}

Aos três dias após a inoculação (Figura 2), foram encontrados apenas juvenis de segundo estádio $\left(\mathrm{J}_{2} \mathrm{a}\right)$ de $M$. enterolobii $(=M$. mayaguensis), tanto no porta-enxerto 'Magnet' quanto em 'Helper M', sendo neste, encontrada a maior porcentagem de $\mathrm{J}_{2}$ a. Após 3 DAI, $M$. javanica ainda não havia penetrado no sistema radicular de 'Magnet', nem de 'Helper M', não sendo encontrado $\mathrm{J}_{2}$ a nestes tomateiros (Figura 2).

A penetração de juvenis de Meloidogyne nos primeiros dias após a inoculação já foi constatada em outros estudos, como os realizados por Moritz et al. (16) e Oliveira (18). Entretanto, Taylor \& Sasser (23) citam haver alta penetração de juvenis de Meloidogyne spp. em períodos inferiores a 24 horas da inoculação. Em tomateiro suscetível 'Rutgers', Costa et al. (7) observaram uma baixa penetração de $\mathbf{J}_{2}$ de M. javanica ao quarto dia após a inoculação, isso devido, 


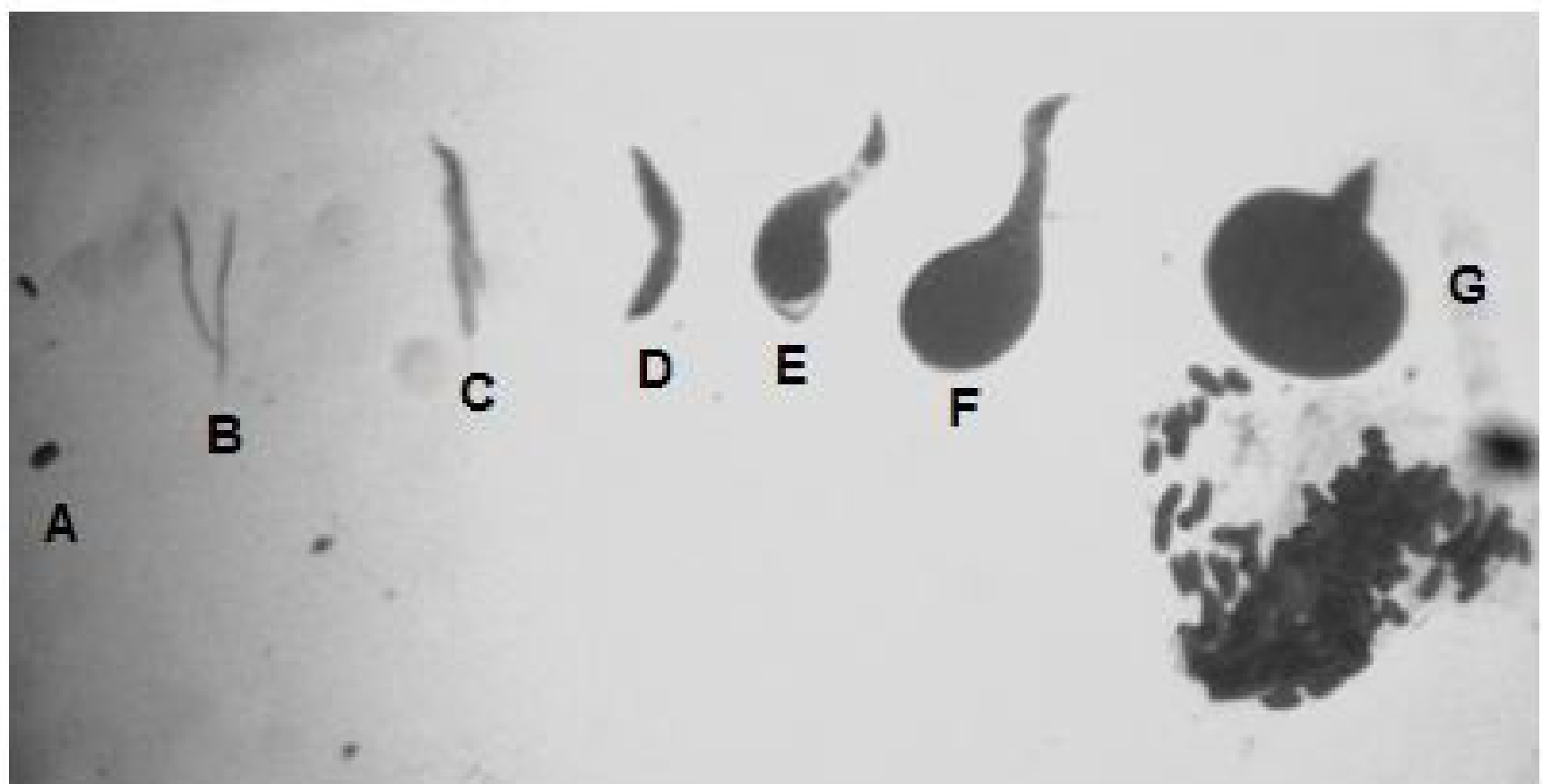

Figura 1. Estádios de desenvolvimento de M. enterolobii. A: Ovo; B: $\mathrm{J}_{2}$ a; C: $\mathrm{J}_{2}$ b; D: $\mathrm{J}_{4}$; E-F: F; G: F [Triantaphyllou \& Hirschmann $(24)$ e Siddiqi \& Taylor (20)].

Época I (3DAI)

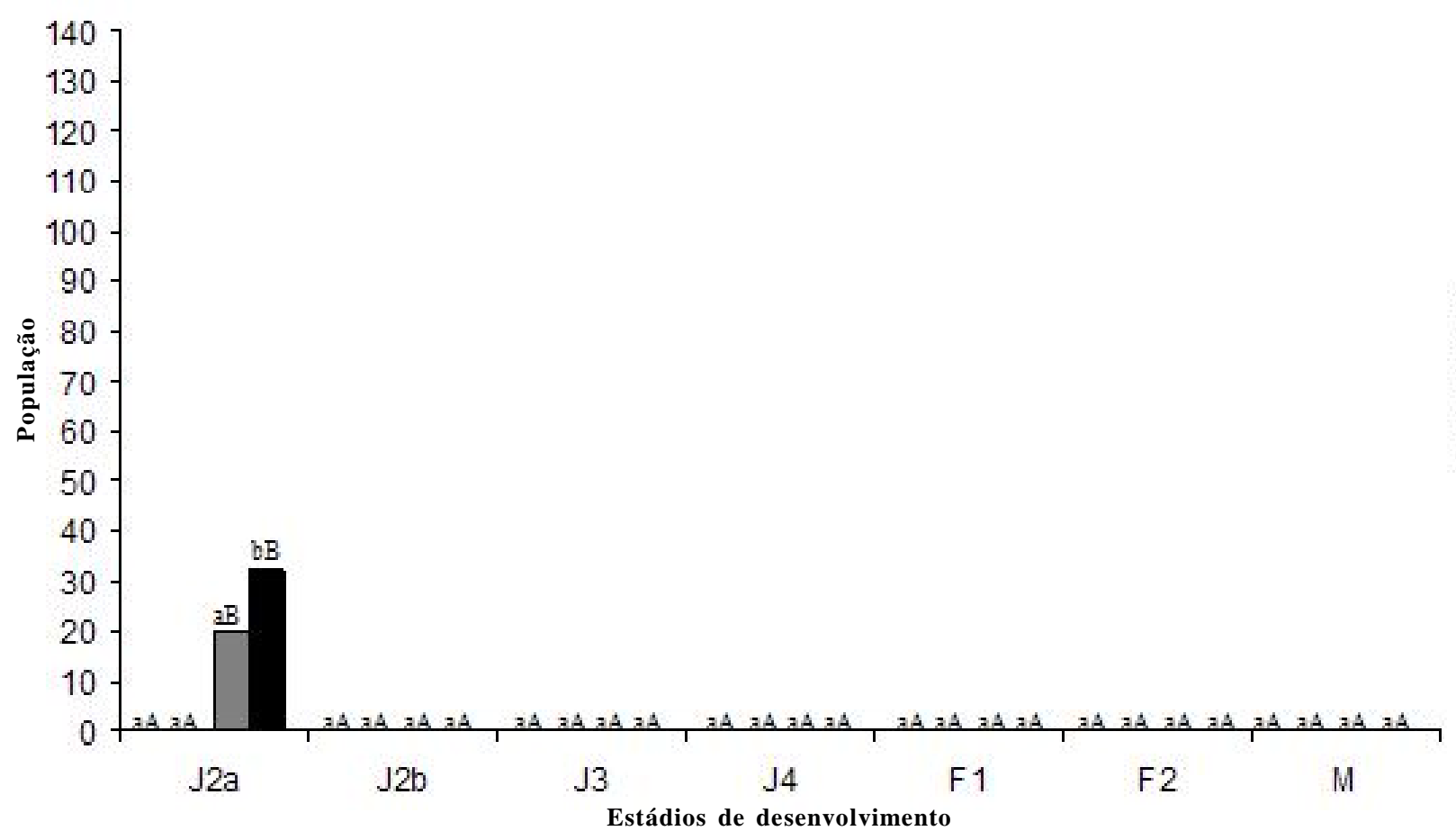

Figura 2. Número de indivíduos dos diferentes estádios de desenvolvimento de Meloidogyne enterolobii (Me) e Meloidogyne javanica (Mj) no sistema radicular dos porta-enxertos de tomateiro 'Magnet' (M) e 'Helper $\mathbf{M}^{\prime}$ ' $(\mathrm{H})$, no $3^{\circ}$ dia após a inoculação.

Letras minúsculas comparam porta-enxertos inoculados com o mesmo nematoide. Letras maiúsculas comparam as espécies de Meloidogyne inoculadas num mesmo porta-enxerto. 


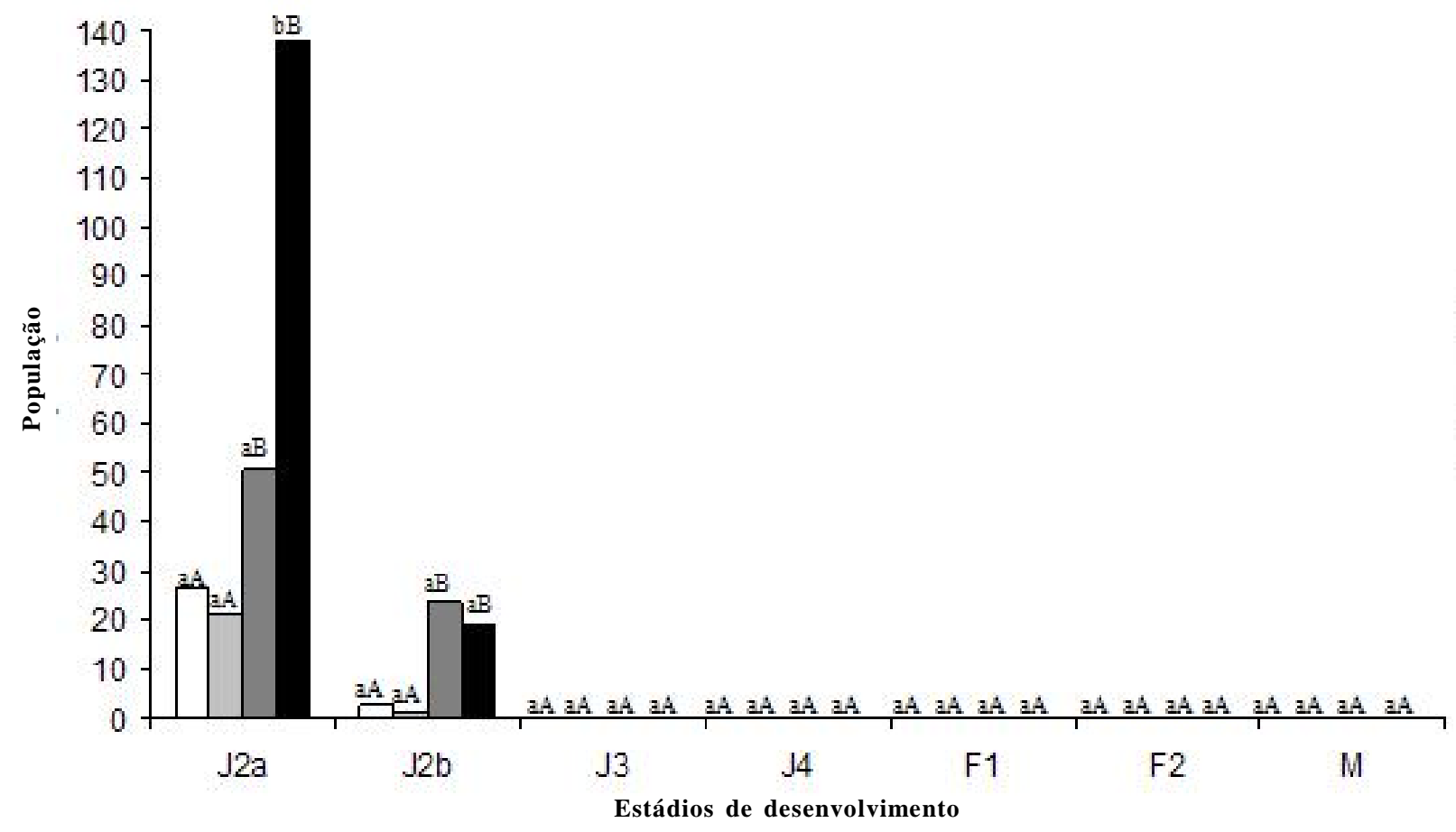

Figura 3. Número de indivíduos dos diferentes estádios de desenvolvimento de Meloidogyne enterolobii (Me) e Meloidogyne javanica (Mj) no sistema radicular dos porta-enxertos de tomateiro 'Magnet' $(\mathrm{M})$ e 'Helper $\mathrm{M}^{\prime}(\mathrm{H})$, no $10^{\circ}$ dia após a inoculação.

provavelmente, por terem utilizado ovos como inóculo.

Aos 10 DAI (Figura 3), foi encontrada a maior taxa de penetração de $\mathrm{J}_{2}$ a de $M$. enterolobii em 'Helper M', sendo esta significativamente maior que em 'Magnet'.

Foi possível observar, já aos 10 DAI, o alargamento dos juvenis $\left(\mathrm{J}_{2} \mathrm{~b}\right)$ de $M$. enterolobii sendo encontrado número significativamente maior de $\mathrm{J}_{2} \mathrm{~b}$ de $M$. enterolobii, em relação a $M$. javanica em ambos os porta-enxertos. Resultados semelhantes foram encontrados por Costa et al. (7), que observaram, em tomateiro suscetível 'Rutgers', a presença de $\mathrm{J}_{2}$ de $M$. javanica exibindo o corpo de forma alargada, tipo "salsicha" $\left(\mathrm{J}_{2} \mathrm{~b}\right)$ aos 8 e 12 DAI. Oliveira (18) observou o alargamento dos $\mathrm{J}_{2}$ de M. incognita a partir do $8^{\circ}$ dia quando inoculados em cafeeiro.

Durante o período de 3 a 10 DAI houve penetração de $M$. javanica, comprovada pelo aumento do número de $\mathrm{J}_{2} \mathrm{a}$ e, também, pela presença de $\mathrm{J}_{2} \mathrm{~b}$ na segunda avaliação (10 DAI), em ambos os porta-enxertos de tomateiro (Figura 3). A taxa de penetração de $\mathrm{J}_{2}$ a de $M$. javanica foi significativamente menor do que a de M. enterolobii tanto em 'Helper M' quanto em 'Magnet', provavelmente devido a algum mecanismo responsável pelo atraso na penetração desta espécie. Este fato sugere que pode haver algum tipo de resistência pré-infectiva como sugerida por Rhode (19), além dos mecanismos de resistência já determinados em tomateiros com o gene $\mathrm{Mi}$.

Aos 17 DAI (Figura 4) foram encontrados $\mathrm{J}_{2}$ a de ambos os nematoides. $\mathrm{O}$ número de $\mathrm{J}_{2}$ a de $M$. javanica foi significativamente maior em 'Helper M' e, embora em pequenas quantidades, foi maior que o número de $\mathrm{J}_{2}$ a de $M$. enterolobii encontrados nesta época de avaliação. Quanto ao tomateiro 'Magnet', não houve diferença na penetração entre as espécies de nematoides.

A porcentagem de $\mathrm{J}_{2} \mathrm{~b}$ de $M$. enterolobii foi significativamente maior em 'Helper M', enquanto a porcentagem de $\mathrm{J}_{4}$ dessa espécie foi significativamente maior em 'Magnet'. Juvenis de terceiro estádio e fêmeas sem ovos de $M$. enterolobii foram encontrados em ambos os porta-enxertos de tomateiro, não havendo diferença entre eles. Costa et al. (7) observaram os estádios $\mathrm{J}_{3}$ e $\mathrm{J}_{4}$ de $M$. javanica em raízes de tomateiro suscetível 'Rutgers' aos 12 DAI, sendo que o maior número destes foi encontrado aos 24 DAI. Em raízes de soja (Glycine max (L.) Merr.), Dias-Arieira et al. (8) observaram um número cada vez mais expressivo de $\mathrm{J}_{3}$ e $\mathrm{J}_{4}$ de $M$. javanica a partir de 12 DAI. Oliveira (18) observou que aproximadamente $54 \%$ dos indivíduos de $M$. incognita de uma população patogênica a cafeeiro se encontravam no estádio $\mathrm{J}_{3}$ ou $\mathrm{J}_{4}$, aos 15 DAI.

Nesta época de avaliação, não foram encontrados $\mathrm{J}_{2} b, \mathrm{~J}_{3}, \mathrm{~J}_{4} \mathrm{e}$ fêmeas sem ovos de $M$. javanica em nenhum dos porta-enxertos, assim como nas demais épocas (Figura 4).

Aos 24 dias após a inoculação (Figura 5), havia no sistema radicular todos os estádios de desenvolvimento de $M$. enterolobii. A porcentagem de $_{2}$ a dessa espécie foi significativamente maior em 'Helper M' (Figura 5). Ainda em relação a $M$. enterolobii, as porcentagens de $\mathrm{J}_{2} \mathrm{~b}, \mathrm{~J}_{4}$, machos e fêmeas com ovos não diferiram entre os porta-enxertos de tomateiro (Figura 5). Já a porcentagem de $\mathrm{J}_{3}$ foi maior em 'Helper M' enquanto a porcentagem de fêmeas sem ovos, maior em 'Magnet'. Costa et al. (7) detectaram fêmeas de $M$. javanica em tomateiro 'Rutgers' aos 20 dias após a inoculação, enquanto Guimarães et al. (11) observaram que o amendoim (Arachis hypogaea L.), espécie imune a $M$. enterolobii, apresentou grande quantidade de indivíduos de diferentes estádios no interior das raízes, não ocorrendo, entretanto, fêmeas adultas com ovos.

A porcentagem de $\mathrm{J}_{2}$ a e $\mathrm{J}_{2} \mathrm{~b}$ de $M$. javanica, aos 24 DAI, não diferiu significativamente entre os porta-enxertos 'Magnet' e 'Helper M'.

Aos 31 dias (Figura 6) foram observados todos os estádios de desenvolvimento de M. enterolobii em ambos os porta-enxertos. Para 


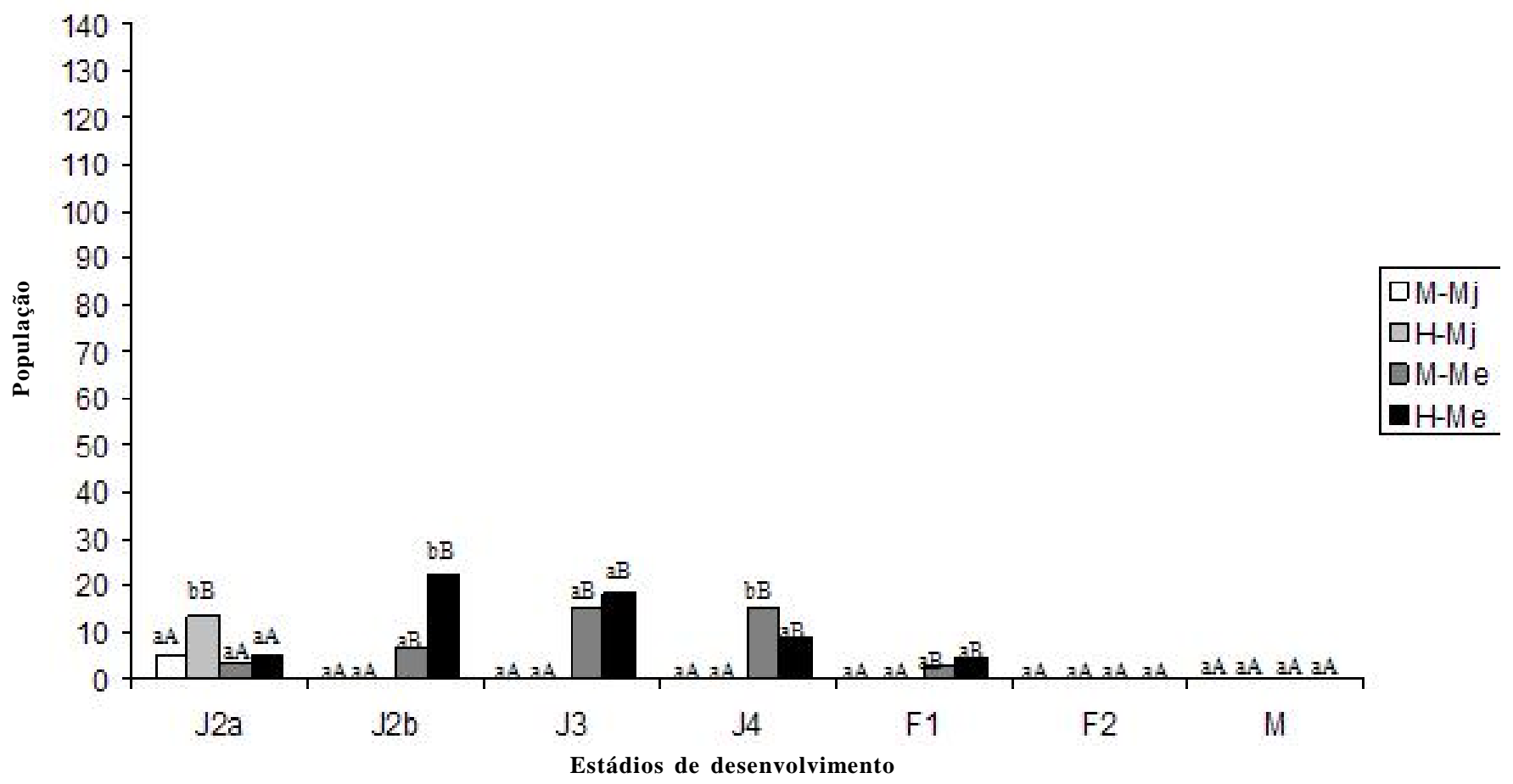

Figura 4. Número de indivíduos dos diferentes estádios de desenvolvimento de Meloidogyne enterolobii (Me) e Meloidogyne javanica (Mj) no sistema radicular dos porta-enxertos de tomateiro 'Magnet' (M) e 'Helper $\mathrm{M}^{\text {' }}(\mathrm{H})$, no $17^{\circ}$ dia após a inoculação.

Época IV (24 DAI)

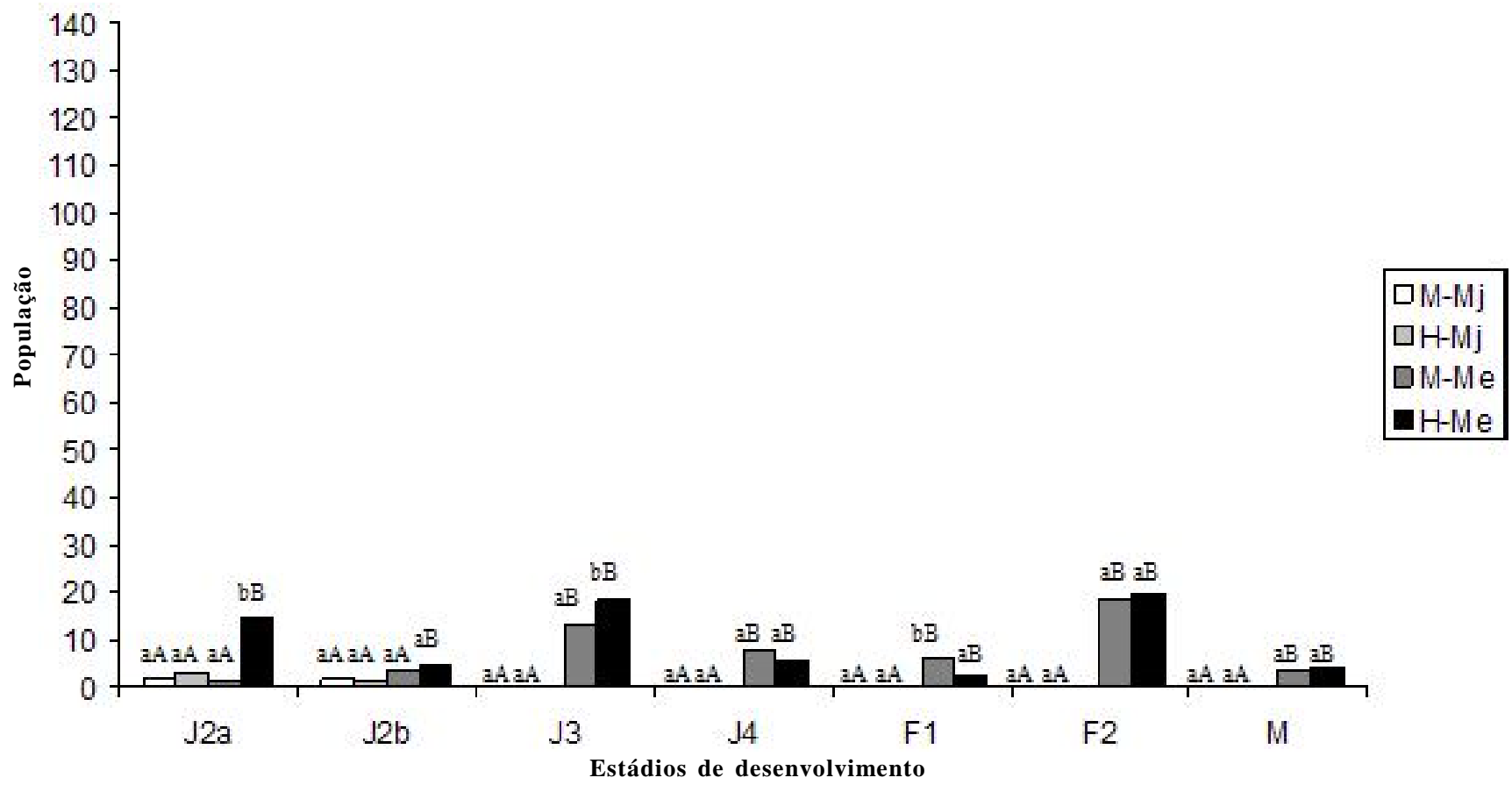

Figura 5. Número de indivíduos dos diferentes estádios de desenvolvimento de Meloidogyne enterolobii (Me) e Meloidogyne javanica (Mj) no sistema radicular dos porta-enxertos de tomateiro 'Magnet' $(\mathrm{M})$ e 'Helper $\mathrm{M}^{\prime}(\mathrm{H})$, no $24^{\circ}$ dia após a inoculação.

essa espécie, a porcentagem de $\mathrm{J}_{2}$ a encontrada foi maior que a encontrada para $M$. javanica. A maior porcentagem de $\mathrm{J}_{2}$ a de $M$. enterolobii foi observada no porta-enxerto 'Magnet'. A ocorrência elevada de $\mathrm{J}_{2} \mathrm{a}$ vários dias após a inoculação, pode ser devido à eclosão dos juvenis após postura das fêmeas encontradas aos 24 DAI (juvenis da nova geração), ou também devido à entrada posterior desses juvenis nos sistemas radiculares. Em 'Helper $\mathbf{M}$ ' foi encontrada as maiores porcentagens de $\mathrm{J}_{3}$ e $\mathrm{J}_{4}$ em relação a 'Magnet', porém este apresentou maior porcentagem de fêmeas sem ovos do que 'Helper M'. Não houve diferença significativa entre os porta-enxertos quanto às 
Época V (31 DAI)

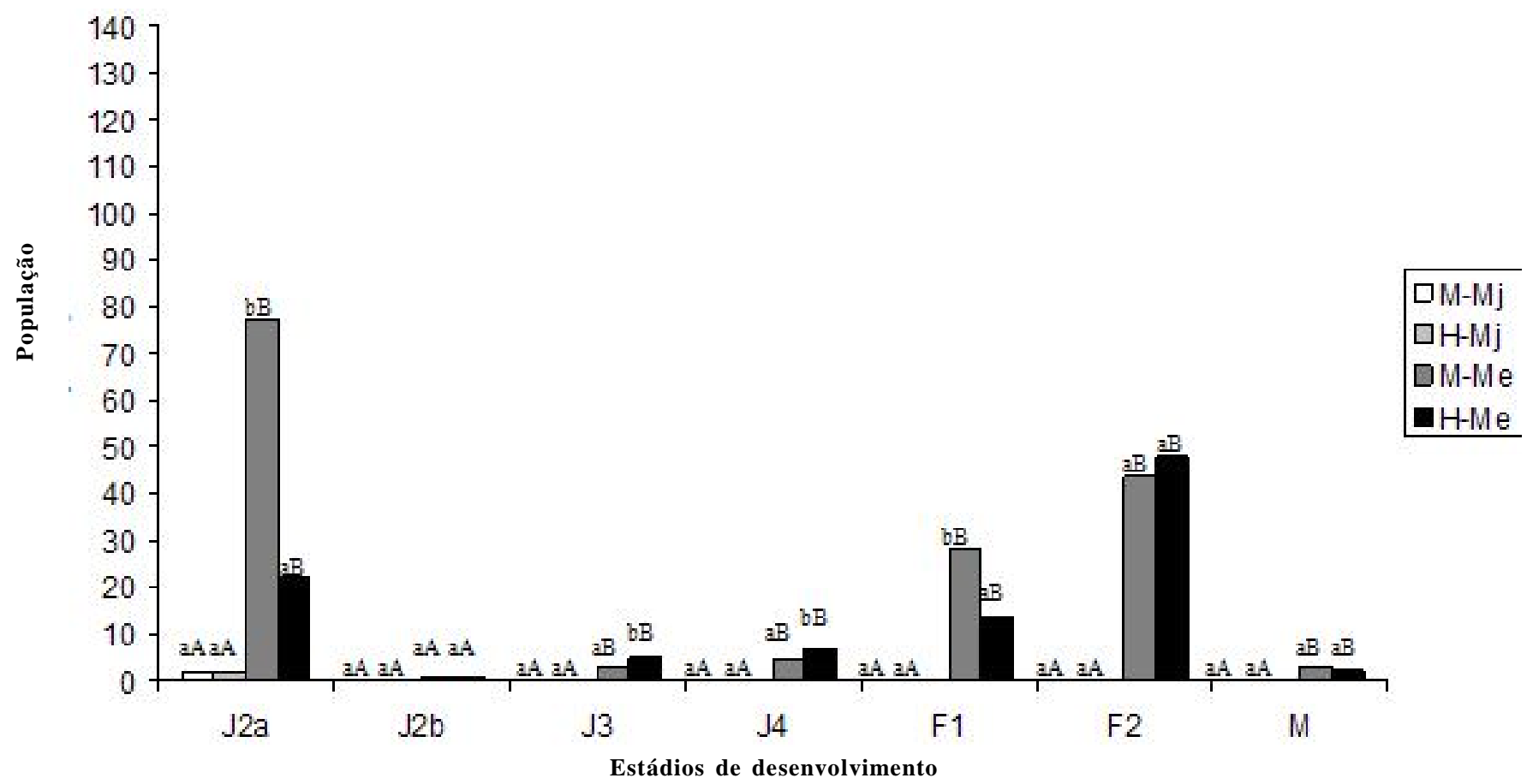

Figura 6. Número de indivíduos dos diferentes estádios de desenvolvimento de Meloidogyne enterolobii (Me) e Meloidogyne javanica (Mj) no sistema radicular dos porta-enxertos de tomateiro 'Magnet' (M) e 'Helper $\mathbf{M}^{\prime}(\mathrm{H})$, no $31^{\circ}$ dia após a inoculação.

porcentagens de $\mathrm{J}_{2} \mathrm{~b}$, machos e fêmeas com ovos. Moritz et al. (16) constataram maior número de fêmeas de $M$. paranaensis Carneiro et al. entre os 22 e 32 dias após a inoculação em um cultivar suscetível de soja, sendo que poucas atingiram esse estádio em um cultivar resistente.

Com isso, M. enterolobii desenvolve-se normalmente, com as fêmeas maduras realizando suas posturas, a partir de 24 dias após a inoculação, a $26^{\circ} \mathrm{C}$.

Aos 31 DAI, $M$. javanica apresentou baixa porcentagem de $\mathrm{J}_{2} \mathrm{a}$, não diferindo significativamente entre os porta-enxertos.

Embora tenham ocorrido diferenças nas porcentagens dos estádios de $M$. enterolobii encontrados em cada porta-enxerto de tomateiro estudado, nas épocas de coleta, isto não comprova a diferença na reação dos porta-enxertos frente a essa espécie. Fato esse comprovado com o prévio trabalho de Cantu et al. (2), que avaliando a reação dos porta-enxertos 'Magnet' e 'Helper M', a M. enterolobii, constataram que 'Magnet' apresentou fator de reprodução 12,05 enquanto 'Helper M' apresentou fator de reprodução igual a 14,92, não havendo diferença significativa entre eles.

Os porta-enxertos utilizados nesse estudo são resistentes à meloidoginose, portadores do gene $M i$, cujo principal mecanismo de resistência é a reação de hipersensibilidade (HR) em tomateiros parasitados por M. incognita, $M$. javanica e $M$. arenaria, conforme Dropkin (9). Isso justifica a presença de apenas indivíduos $\mathbf{J}_{2}$ a e $\mathbf{J}_{2} \mathrm{~b}$ nos sistemas radiculares das plantas inoculadas com $M$. javanica. Herman et al. (13) e Carpenter \& Lewis (6), estudando interações entre Meloidogyne spp. e soja, observaram que a reação de resistência da planta não depende necessariamente de sua capacidade de impedir ou dificultar a penetração dos $\mathrm{J}_{2}$, mas possivelmente esteja em alguma etapa posterior do parasitismo, como no estabelecimento do sítio de alimentação, por exemplo.

Com isso, conclui-se que existe a necessidade de obtenção de porta-enxertos resistentes a $M$. enterolobii, uma vez que essa espécie encontra-se bastante distribuída pelo Brasil causando danos não só em tomateiros, como em diversas culturas de valor econômico para o país.

\section{REFERÊNCIAS BIBLIOGRÁFICAS}

1. Bonetti, J.I.S.; Ferraz, S. Modificação do método de Hussey e Barker para extração de ovos de Meloidogyne exigua de raízes de cafeeiro. Fitopatologia Brasileira, Brasília, v.6, n.3, p.553, 1981.

2. Cantu, R.R.; Wilcken, S.R.S.; Rosa, J.M.O.; Goto, R. Reação de porta-enxertos de tomateiros a Meloidogyne mayaguensis. Summa Phytopathologica, Botucatu, v.35, p.124-126, 2009.

3. Carneiro, R.M.D.G.; Almeida, M.R.A. Técnica de eletroforese usada no estudo de enzimas dos nematóides de galhas para identificação de espécies. Nematologia Brasileira, Brasília, v.25, n.1, p.35-44, 2001.

4. Carneiro, R.M.D.G.; Almeida, M.R.A.; Braga, R.S.; Almeida, C.A.de; Gioria, R. Primeiro registro de Meloidogyne mayaguensis parasitando plantas de tomate e pimentão resistentes a meloidoginose no estado de São Paulo. Nematologia Brasileira, Brasília, v.30, n.1, p.81-86, 2006.

5. Carneiro, R.M.D.G.; Moreira, W.A.; Almeida, M.R.A.; Gomes, A.C.M.M. Primeiro registro de Meloidogyne mayaguensis em goiabeira no Brasil. Nematologia Brasileira, Brasília, v.25, n.2, p.223-228, 2001

6. Carpenter, A.S.; Lewis, S.A. Aggressiveness and reproduction of four Meloidogyne arenaria populations on soybean. Journal of Nematology, Lake Alfred, v.23, n.2, p.232-238, 1991.

7. Costa, D.C.; Ferraz, S.; Caldas, R.C. Estudo comparativo da penetração e desenvolvimento de Meloidogyne javanica em raízes de guandu e tomateiro. Nematologia Brasileira, Brasília, v.22, n.2, p.80-86, 1998.

8. Dias-Arieira, C.R.; Ferraz, S.; Freitas, L.G.; Mizobuts, H. Pene- 
tração e desenvolvimento de Meloidogyne incognita, M. javanica e Heterodera glycines em quatro gramíneas forrageiras. Nematologia Brasileira, Brasília, v.26, n.1, p.35-41, 2002.

9. Dropkin, V.H. The necrotic reaction of tomatoes and other hosts resistant to Meloidogyne: reversal by temperature. Phytopathology, Palo Alto, v.59, n.11, p.1632-1637, 1969.

10. Ferreira, D.F. Sisvar. Versão 4.2. Lavras: DEX/UFLA, 2003. $79 \mathrm{p}$.

11. Guimarães, P.M.; Leal-Bertioli, S.C.M.; Seijo, G.; Parniske, M.; Stougard, J.; Bertioli, D. The identification of resistances to biotic stress in wild Arachis germplasm, and the development of tools for breeding by genetic mapping and comparative genomics. In: International Congress of Plant Molecular Biology, 7., 2003, Barcelona. Proceedings. Barcelona: ISPMB Office, 2003a. p.23-28.

12. Guimarães, L.M.; Moura, R.M.; Pedrosa, E.M.R. Parasitismo de Meloidogyne mayaguensis em diferentes espécies botânicas. Nematologia Brasileira, Brasília, v.27, n.2, p.139-145. 2003b.

13. Herman, M.; Hussey, R.S.; Boerma, H.R. Penetration and development of Meloidogyne incognita on roots of resistant soybean genotypes. Journal of Nematology, Lake Alfred, v.23, n.2, p.155-161, 1991.

14. Hussey, R.S.; Baker, K.R. A comparison of methods of collecting inocula of Meloidogyne species, including a new technique. Plant Disease Report, Saint Paul, v.57, p.1025-1028, 1973.

15. Hussey, R.S.; Janssen, G.J.W. Root-knot nematodes: Meloidogyne species. In: Starr, J.L.; Cook, R.; Bridge, J. Plant resistance to parasitic nematodes. Wallingford, UK: CAB International, 2002. p.43-70.

16. Moritz, M.P.; Carneiro, R.G.; Santiago, D.C.; Nakamura, K.C.; Pignoni, E.; Gomes, J.C. Estudo comparativo da penetração e reprodução de Meloidogyne paranaensis em raízes de cultivares de soja resistente e suscetível. Nematologia Brasileira, Piracicaba, v.32, n.1, p.33-40, 2008.
17. Moura, R.M. O gênero Meloidogyne e a meloidoginose: parte II. RAPP, Passo Fundo, v.5, p.281-315, 1997.

18. Oliveira, D.S. Patogenicidade de populações de $M$. incognita, provenientes de Minas Gerais e São Paulo, ao cafeeiro. 2006. 75f. Tese (Doutorado em Agronomia/Fitopatologia)-Universidade Federal de Viçosa, Viçosa.

19. Rhode, R.A. The expression of resistance in plants to nematode. Annual Review Phytopathology, Palo Alto, v.10, p.233-252, 1972.

20. Siddiqui, I.A.; Taylor, D.P. Histopathogenesis of galls induced by Meloidogyne naasi in wheat roots. Journal of Nematology, Jay, v.2, n.3, p.239-247, 1970.

21. Southey, J.F. (Ed.). Principles of sampling for nematodes: Laboratory methods for work with plant and soil nematodes. 6th ed. London: Ministry of Agriculture, Fisheries and Food, 1986. 202p.

22. Taylor, B. Biosistematics of the tomato. In: Atherton, J.G.; Rudich, J. The tomato crop: a scientific basis for improvement. New York: Chapman and Hall, 1986. p.1-30.

23. Taylor, A.L.; Sasser, J.N. Biology, identification and control of root-knot nematodes (Meloidogyne sp.). Raleigh: North Carolina State University Graphics, 1978. 111p.

24. Triantaphyllou, A.C.; Hirschmann, H. Post infection development of Meloidogyne incognita Chitwood 1949 (Nematoda: Heteroderidae). Annales de L'Institut Phytopathologique Benaki, New Series, v.3, p.1-11, 1960

25. Xu, J.; Peilei, L.; Qingpeng, M.; Hai, L. Characterisation of $M e-$ loidogyne species from China using isozyme phenotypes and amplified mitochondrial DNA restriction fragment length polymorphism. European Journal of Plant Pathology, v.110, p.309-315, 2004.

26. Yang, B.; Eisenback, J.D. Meloidogyne enterolobii n. sp. (Meloidogynidae), a root knot nematode parasitising pacara earpod tree in China. Journal of Nematology, v.15, p.381-391, 1983 